\title{
USING LOGARITHMIC FUZZY PREFERENCE PROGRAMMING TO PRIORITIZATION SOCIAL MEDIA UTILIZATION BASED ON TOURISTS' PERSPECTIVE
}

\author{
Mina BALOUCHI*, Ehsan KHANMOHAMMADI** \\ * University of Tehran, Faculty of Management, Department of Business Management, Iran \\ e-mail: Mina.Balouchi@gmail.com \\ ${ }^{* *}$ University of Tehran, Faculty of Management, Department of Industrial Management, Iran
}

\begin{abstract}
The advent of Web 2.0 or social media technologies gives travelers a chance to access quickly and conveniently to a mass of travel-related information. This study investigates the importance of social media in travel process in three different phases (pre-visit, on site, post-visit) from the perspective of Iranian travelers. It is worthwhile to know the level of influence of social media on respondents' travel behavior. Logarithmic fuzzy preference programming methodology is used in this article to determine the importance of social media usage in each phase of travel process and its subcategories. Fuzzy analytic hierarchy process methodology, based on Chang's Fuzzy Extent Analysis is also used for the data analysis, then the results of these two methods are presented for comparison and better understanding. The results of this study suggest that the most usage of social media is on previsit phase while post-visit has the least usage. This study shows that Iranian travelers use social media mainly to share experiences (post-visit phase), get help in different circumstances and gain travel advice.
\end{abstract}

Keywords: social media, LFPP, travel process, user generated content, tourism marketing.

\section{Introduction}

Web 2.0 or social media technologies provide a platform for interactive means of communication [1]. Reference [2] by implying the significant influence of Internet in tourism marketing suggested that the best way to access to the travel-related information is still through social media. As they defined, the advent of the Web 2.0 developed Internet-based online media and "shift the power" from institution to consumers (p. 1). In other words, because of the emergence of social media technologies and their impact on tourism industry, marketing for tourism product is facing a challenge, because the control of tourism content is no longer in organizations hand and it has been bestowed to the tourism product consumers. Both tourism organizations and businesses productrelated procedures and tourists' experience have been touched by the introduction of information technologies. Evolution of Internet has challenged current interaction between tourists and businesses and is moving toward consumer-to-consumer communication [1].

With the prevalence of social media, travel-related activities such as the ways that travelers gain information, plan their trips and share their experiences with other potential travelers have changed fundamentally [3]. The presence of social media allows tourists to share their travel-related experiences and communicate with other people. Social media provides a unique opportunity for tourists to publish every travel-related contents they wish for it and for a great number of audiences, and this is despite what have been happening in the past, when they only were able to share their information with limited number of people.

Social media facilitates the exchange of information among users, as there are many different ways of communication through Internet. For instance, social networking sites such as Facebook, Twitter, and TripAdviser allow users to post their ideas, while other sites such as Instagram and Flickr allow their users to share photos or even videos such as YouTube. These social media have a great impact on tourism decision behavior, for example, Instagram [4] has more than 300 million active users who uploaded more than 60 million photos per day. In other example, TripAdviser.com [5] claims that there are more than 200 million reviews and opinions from travelers around the world. This number demonstrated a significant increase from 2002 as shown in [6] (75 million post by users). 


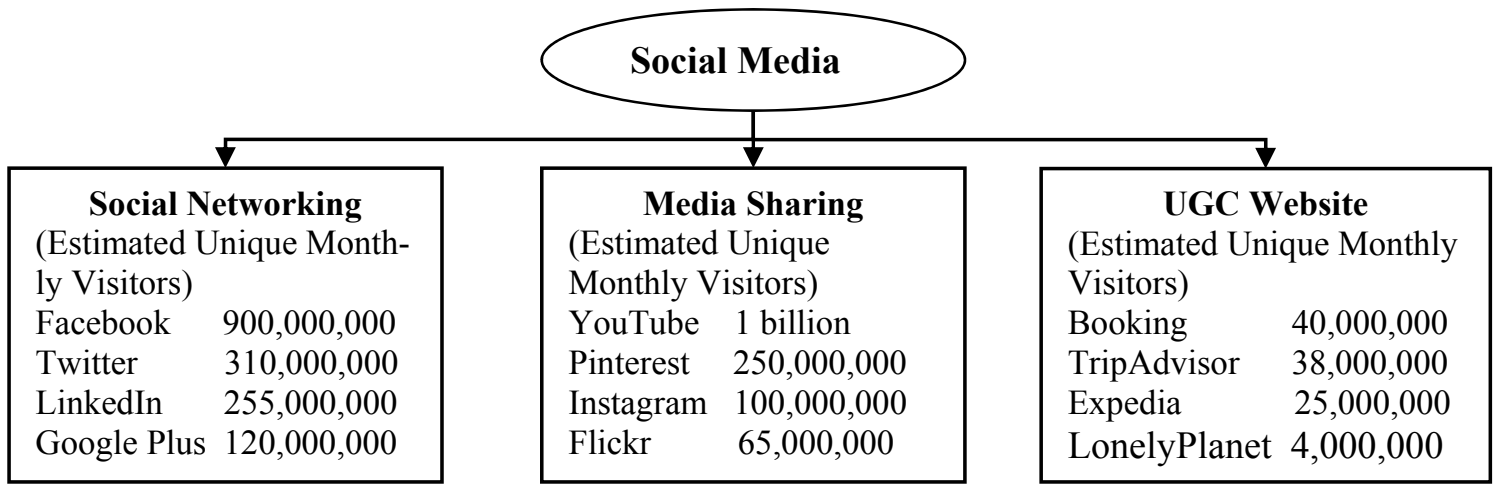

Figure 1. Social media categories $[10,11]$

For many years, researchers have documented the importance of social media in decision-making procedures; however, little has explored how much travelers rely on social media in each stages of their trip. This paper propose a framework for examining how travelers use social media and how different aspects of this usage shape tourism consumers' behavior. This study tries to highlight Iranian tourism consumers' preference in using social media for travel and tourism marketing and examines to what extent social media is being used on different stages of travel process. In other word, this paper is going to evaluate relative importance degree of each factor for Iranian tourism consumers on each of the mentioned stages with logarithmic fuzzy preference programming (LFPP). The finding of this study would benefit travel and tourism marketing by showing how social media impacts on travel-related experience among current and potential consumers.

The remainder parts of this paper is organized as follows: first, a brief background of the existing literature on the subject of social media and tourism and their relation is demonstrated. Then the criteria and subcriteria of this study is introduced in Section 2. In the methodology section, the research steps of this paper are illustrated and an overview of the methods used here is mentioned. Finally, results and findings of this paper is presented and discussed in detail.

\section{Literature review}

- Impacts of social media

Social media (Web 2.0) concept revealed for the first time in late 2004 and it works based on contents that are generated by users as main contributors, and since then, the growth in social media and communication technology has been dramatic. Therefore, consumption, creation, and dissemination of information have been radically changed by social media [3]. As Buhalis [7] stated, Internet technology "constantly increase computing speed; decrease equipment size; reduce hardware and software costs; and improve the reliability, compatibility and interconnectivity of numerous terminals and applications" (p. 1).

Reference [8] stressed that Web 2.0 is a "platform whereby content and applications are no longer created and published by individuals, but instead are continuously modified by all users in a participatory and collaborative fashion" (p. 61). Online sharing of consumer-generated contents becomes one of the main component of constantly developing social media [3]. Social media can be divided into three main categories as shown in Fig. 1. As shown in Fig. 1 , social media is a popular source of information among users and, therefore, enhances content dissemination for marketing business purposes. Through social media any one in everywhere can access all the information they need.

For instance, Nielsen [9] conducted a Global Online Consumer Survey and the result showed that $70 \%$ of people trust consumer opinions that are posted online, and it was positioned in second place after the recommendations from people known to them, which was in first place by $90 \%$. However, in 2011, based on a survey conducted by Thinktravel with Google revealed that the Internet became the leading source for travel planning information. The result demonstrates that $85 \%$ of respondent use Internet for their travel planning, while only $60 \%$ of people rely on their family, friends, or colleagues [12]. 
Table 1. Criteria and sub-criteria used in this study for social media users

\begin{tabular}{|c|c|c|}
\hline Criteria & Alternatives & Author(s) \\
\hline Pre-visit phase & $\begin{array}{l}\text { gain travel advice } \\
\text { inspiration } \\
\text { products comparison } \\
\text { information about attractions } \\
\text { information about destinations } \\
\text { purchase travel products }\end{array}$ & $\begin{array}{l}\text { Casaló et al. [25], Munar and Jacobsen [26] } \\
\text { Bosun et al. [27], Buhalis and Wagner [28] } \\
\text { Strachan [29], Teng et al. [30] } \\
\text { Xiang et al. [31], Fesenmaier et al. [32] } \\
\text { Hay [33], Xiang et al. [31] } \\
\text { Amaro and Duarte [34], Jensen [35] }\end{array}$ \\
\hline On site phase & $\begin{array}{l}\text { get help in different circumstances } \\
\text { get help in difficult situations } \\
\text { on location travel planning } \\
\text { continue daily routines } \\
\text { share experiences }\end{array}$ & $\begin{array}{l}\text { Wang and Fesenmaier [36] } \\
\text { Wang and Fesenmaier [36] } \\
\text { Kurup [37], Fotis et al. [38] } \\
\text { Fotis et al. [38] } \\
\text { Li and Hua [39] }\end{array}$ \\
\hline Post-visit phase & $\begin{array}{l}\text { share experiences } \\
\text { satisfaction } \\
\text { recommend } \\
\text { warn } \\
\text { purchase decision }\end{array}$ & $\begin{array}{l}\text { Fotis et al. [40], Lenhart and Fox [41] } \\
\text { Yoo and Gretzel [42] } \\
\text { Wilson et al. [43], Bosun et al. [27] } \\
\text { Wilson et al. [43], Sparks and Browning [44] } \\
\text { Huang et al. [45] }\end{array}$ \\
\hline
\end{tabular}

\section{- Social media and tourism}

Increasing use of Internet and social media have influenced tourism next to other industries as Yoo et al. [13] claimed "they are taking an important role in travelers' information search and decision-making behaviors" (p. 526). Nowadays, the use of social media for tourism businesses has altered, as Internet becomes one of the most effective means of communication and information search [14]. Both tourists and tourism businesses use the Internet widely [7]. With the current innovation in technologies, which is the result of the growth of social media, tourism destinations, managers should consider that as competitive advantage and be aware of any future changes that it may imply on supply and distribution processes and tourism product consumers' behavior [1]. Tourism organizations [15] are also among those who use social media as a key factor to a successful business. Fuchs et al. [16] mentioned that managers of Destination Marketing Organizations are aware of the relation between information and communications technology (ICT) utilization and the competitive ability and indicated that experiences of key decision makers and context of environment should be considered before adoption of new technologies.

The availability of social media to consumers is its privilege as "tourists may require different kinds of information at different stages of the trip" [14]. By using social media, tourist can now engage ac- tively in contents of the Web site rather than be a simple visitor as they were in the past [17]. Kaplan and Haenlein first claimed that advancements in ICT will change consumer behavior in tourism. Later, Gretzel et al. predicted that the impacts of social media on travel industry will be enormous. Following examples prove that their prediction was quite correct. World Tourism Organization [19] revealed that the role of social media and user-generated content (UGC) has been investigated in many different study. For example, Tussyadiah and Fesenmaier [20] examined videos posted on social media regarding to tourism, while Wenger [21] explored weblogs and their contents and Xiang and Gretzel [22] explored different travel sites. Many survey have been conducted to explore the role of social media in travel decision as well. In a survey, eMarketer [23] indicated that $61 \%$ of American checked online reviews and feedbacks before they decided to purchase a travel package.

In a study conducted by Chung and Buhalis [24], the factors that have effect on the participation of Internet users in social media were investigated and the result showed that information acquisition besides hedonic and social benefits are the most important reasons for the contribution of users in online communities. However, this category is quite broad; this study tries to investigate the importance of social media for Iranian tourists in three criteria and 16 
alternatives in detail by examining the following categories precisely.

- Criteria and alternatives selection

Table 1 summarizes three major criteria and 16 alternatives used in this study that represent the characteristic of what social media users in tourism industry emphasize currently.

\section{$3 \quad$ Methodology}

In Fig. 2 research steps of this paper are explained and demonstrated.

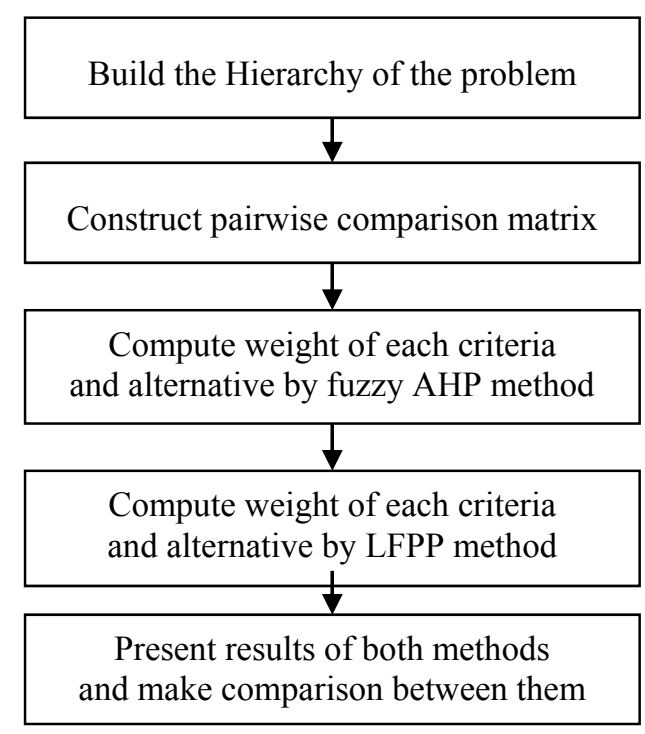

Figure 2. Research steps

As it is shown in the Fig. 2, first, the hierarchy of the problem is formed and developed. Then, pairwise comparison matrix is established.

After that, the weight of each criteria and alternative is computed using two mentioned methods, fuzzy analytic hierarchy process (AHP) and LFPP. Finally, the results of each method is analyzed and evaluated, and a comparison between results is presented.

This section of the study consists of several steps, each steps is described in detail in the following.

\section{- Overview of AHP, Fuzzy AHP and LFPP}

AHP was initially introduced by Satty [46], as a method of solving complex multicriteria decisionmaking (MCDM) problems. In a broader definition, "the fuzzy set theory approaches could resemble human reasoning in use of approximate information and uncertainty to generate decisions. Furthermore, fuzzy logic has been integrated with multi criteria decision making (MCDM) to deal with vagueness and imprecision of human judgment" [47]. As Safari et al. [48] stressed, MCDM refers to a decisionmaking situation that deals with different aspects of certain group of variables.

Qualitative criteria could be analyzed by AHP in order to assign weigh of the alternatives and enable decision makers to organize problems with complexity to a plain hierarchy form. AHP provides a structure to combine rational and irrational values during the process of making decision using a pairwise comparison approach $[49,50]$. Four major steps of AHP technique are as follows [51, 52]:

1) Structure a hierarchy of decision factors and elements (AHP decision model);

2) Employ pairwise comparison using inputs from users to establish relative importance of criteria;

3) Estimate relative weight at each level of the hierarchy;

4) Aggregate relative importance weight to obtain set of ratings and ranking for decision alternatives.

AHP, despite of its abilities in capture expert's knowledge, because of its crisp numbers compare to fuzzy AHP interval values, cannot reflect human thoughts completely. Fuzzy AHP is created by Zadeh, a well-known electronic engineer to deal with hierarchy fuzzy problems using mathematical method [53]. Fuzzy AHP models are designed for diverse problems related to needs and interests of people [54]. Thus, fuzzy AHP, that is, a fuzzy extension of AHP, is used for solving fuzzy MCDM problems, with fuzzy numbers that alter vague information to a set of useful data. The criteria values that are provided by experts are in the form of linguistic variables.

Fuzzy AHP because of its capability in dealing with fuzziness and solving MCDM is a popular methodology, and it is expected that to find more applications as judgments in fuzzy environment is way more easier than judgments in crisp environment. There are two methods for deriving the weights from the matrix of paired comparisons by using fuzzy AHP: the first method is to extract a set of fuzzy weights from the fuzzy paired comparisons matrix (including geometric mean, the objective linear programming, 
and fuzzy logarithmic least squares method), while the second one is to extract a set of crisp weights from the fuzzy paired comparisons matrix (including fuzzy preference programming (FPP) - based nonlinear method and extent analysis).

Chang [55] proposed an extent analysis method that allowed fuzzy AHP weight derivation in a simple way. However, Wang et al. [56] proved the invalidity of this method. The FPP-based nonlinear priority is also another method whose drawback has been proved. Section 3.4 shows how Wang et al. [57] provided an LFPP-based methodology that attains crisp priorities from fuzzy pairwise comparison matrices [57].

\section{- Linguistic variables}

Linguistic variables use linguistic expressions to demonstrate uncertain values and represent the decision-maker's preference of one alternative over another. When the information provided in a study cannot be stated in a solid quantitative form, the study use linguistic terms. Therefore, linguistic assessments would be used to give a measure instead of real numerical values [58, 59]. For the purpose of this study, nine Iranian experts were asked to use linguistic term provided to them in order to express their preference on alternatives as shown in Table 2 [60]. Later, this table can be used to convert this fuzzy linguistic variables to fuzzy number. The assessment value for these variables can be assigned as "Equally important," "Weakly more important," "Strongly more important," "Very strongly more important," and "Absolutely more important." Then each linguistic value would be characterized by a triangular fuzzy number, as it ranges between 1 and 9 in order to reflect the fuzziness of the terms.

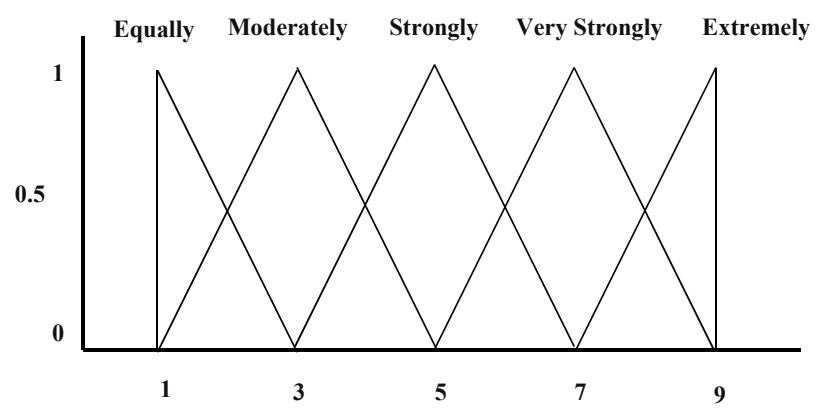

Figure 3. Fuzzy linguistic assessment variables

Table 2. Fuzzy linguistic assessment variables

\begin{tabular}{|c|c|c|c|}
\hline Linguistic Scale & $\begin{array}{c}\text { Fuzzy } \\
\text { Numbers }\end{array}$ & Domain & $\begin{array}{c}\text { Triangular } \\
\text { Fuzzy Scale }\end{array}$ \\
\hline Just Equall & \multirow{2}{*}{1} & & $(1,1,1)$ \\
\hline Equally important & & $1 \leq x \leq 3$ & $(1,1,3)$ \\
\hline \multirow{2}{*}{ Weakly more important } & \multirow{2}{*}{3} & $1 \leq \mathrm{x} \leq 3$ & \multirow{2}{*}{$(1,3,5)$} \\
\hline & & $3 \leq x \leq 5$ & \\
\hline \multirow{2}{*}{ Strongly more important } & \multirow{2}{*}{5} & $3 \leq x \leq 5$ & \multirow{2}{*}{$(3,5,7)$} \\
\hline & & $5 \leq x \leq 7$ & \\
\hline \multirow{2}{*}{ Very strongly more important } & \multirow{2}{*}{7} & $5 \leq x \leq 7$ & \multirow{2}{*}{$(5,7,9)$} \\
\hline & & $7 \leq x \leq 9$ & \\
\hline Absolutely more important & 9 & $7 \leq x \leq 9$ & $(7,9,9)$ \\
\hline
\end{tabular}

In this paper, both fuzzy AHP and LFPP methods are used for data analysis and then their results are going to be compared for better understanding.

\section{- Fuzzy AHP method}

Definition 1. [60] Triangular fuzzy number (TFN): A fuzzy number $N$ on $\Re$ is defined to be a TFN if its membership function $\mu_{\mathrm{N}}(\mathrm{x}): \Re \rightarrow[0,1]$ be:

$$
\mu_{N}(x)=\left\{\begin{array}{cc}
\frac{x-1}{m-1}, & 1 \leq x \leq m, \\
\frac{u-x}{u-m}, & m \leq x \leq u, \\
0, & \text { otherwise, }
\end{array}\right.
$$

where $\mathrm{l}$, and $\mathrm{u}$ are the lower and upper bounds of the support $\mathrm{N}$ respectively; $\mathrm{m}$ is the modal value; and $\mathrm{l}<\mathrm{m}<\mathrm{u}$. This triangular fuzzy number can be noted by the triple $(\mathrm{l}, \mathrm{m}, \mathrm{u})$. 
This paper adopt [55] fuzzy extent analysis, which is summarized in the following steps.

Step 1. Computing the normalized value of row sums (i.e., fuzzy synthetic extent) by fuzzy arithmetic operations:

$$
\mathrm{S}_{\mathrm{k}}=\sum_{\mathrm{j}=1}^{\mathrm{n}} \mathrm{M}_{\mathrm{kj}} *\left[\sum_{\mathrm{i}=1}^{\mathrm{m}} \sum_{\mathrm{j}=1}^{\mathrm{n}} \mathrm{M}_{\mathrm{ij}}\right]^{-1}
$$

Step 2. Computing the degree of possibility:

The degree of possibility of $M_{2}=\left(a_{2}, b_{2}, c_{2}\right) \geq$ $\mathrm{M}_{1}=\left(\mathrm{a}_{1}, \mathrm{~b}_{1}, \mathrm{c}_{1}\right)$ is defined as:

$$
\mathrm{V}\left(\mathrm{M}_{1} \geq \mathrm{M}_{2}\right)=\sup \left[\min \left(\mu_{\mathrm{M}_{1}}(\mathrm{x}), \mu_{\mathrm{M}_{2}}(\mathrm{y})\right)\right]
$$

which can be equivalently expressed as

$$
\begin{aligned}
& V\left(M_{1} \geq M_{2}\right)=\operatorname{hgt}\left(M_{1} \cap M_{2}\right)=\mu_{M_{2}}(d) \\
& = \begin{cases}1, & \text { if } b_{1} \geq b_{2} \\
0, & \text { if } a_{1} \geq c_{2} \\
\frac{a_{1}-c_{2}}{\left(b_{2}-c_{2}\right)-\left(b_{1}-a_{1}\right)}, & \text { otherwise }\end{cases}
\end{aligned}
$$

where $\mathrm{d}$ is the ordinate of the highest intersection point $\mathrm{D}$ between $\mu_{\mathrm{M}_{1}}$ and $\mu_{\mathrm{M}_{2}}$. To compare $M_{1}$ and $M_{2}$, we need the values of both $V\left(M_{1} \geq\right.$ $\left.M_{2}\right)$ and $V\left(M_{2} \geq M_{1}\right)$ given in Fig. 4.

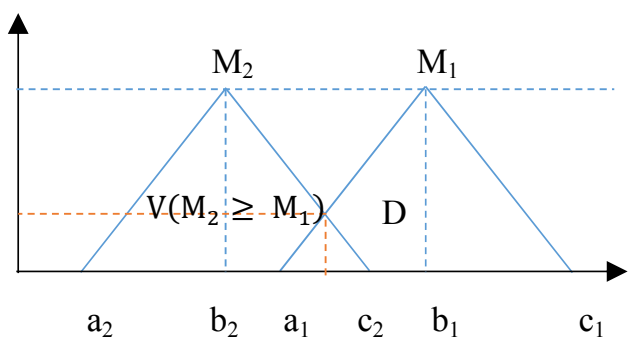

Figure 4. Highest intersection point $D$ between $M_{1}$ and $M_{2}$

The degree of possibility for a convex fuzzy number to be greater than $\mathrm{k}$ convex fuzzy numbers $\mathrm{M}_{\mathrm{i}}(\mathrm{i}=$ $1,2, \ldots, \mathrm{k})$ can be defined as

$\mathrm{V}\left(\mathrm{M} \geq \mathrm{M}_{1}, \mathrm{M}_{2}, \ldots, \mathrm{M}_{\mathrm{k}}\right)=\mathrm{V}\left[\left(\mathrm{M} \geq \mathrm{M}_{1}\right),(\mathrm{M} \geq\right.$ $\left.\left.M_{2}\right), \ldots,\left(M \geq M_{k}\right)\right]=\min \left(M \geq M_{i}\right)$

where $\mathrm{i}=1,2, \ldots, \mathrm{k}$. Assume that:

$$
\mathrm{d}^{\prime}\left(\mathrm{A}_{\mathrm{i}}\right)=\min \mathrm{V}\left(\mathrm{M} \geq \mathrm{M}_{\mathrm{i}}\right)
$$

where $\mathrm{k}=1,2, \ldots, \mathrm{n} ; \mathrm{k} \neq \mathrm{i}$. Then, the weight vector is given by:

$$
W^{\prime}=\left(d^{\prime}\left(A_{1}\right), d^{\prime}\left(A_{2}\right), \ldots, d^{\prime}\left(A_{n}\right)\right)^{T}
$$

where $A_{i}(i=1,2, \ldots, n)$ are $n$ decisions elements.

The normalized weight vectors are:

$$
W=\left(d\left(A_{1}\right), d\left(A_{2}\right), \ldots, d\left(A_{n}\right)\right)^{T}
$$

where $W$ is a non-fuzzy number.

\section{- LFPP method}

In this paper LFPP method is used for data analyses and deriving the weights. LINGO software is also used to solve LFPP problems in order to increase the accuracy and obtain more precise results. The LFPP method is summarized in the following procedures.

FPP-based nonlinear priority model [62] and its constraints is as follow:

Maximize $\lambda$

$$
\text { Subject to }\left\{\begin{array}{l}
-w_{i}+l_{i j} w_{j}+\lambda\left(m_{i j}-l_{i j}\right) w_{j} \leq 0, \\
i=1, \ldots, n-1 ; j=i+1, \ldots, n, \\
w_{i}-u_{i j} w_{j}+\lambda\left(u_{i j}-m_{i j}\right) w_{j} \leq 0, \\
i=1, \ldots, n-1 ; j=i+1, \ldots, n, \\
\sum_{i=1}^{n} w_{i}=1, \\
w_{i} \geq 0, i=1, \ldots, n .
\end{array}\right.
$$

which by the following equivalent FPP is converted to LFPP:

$$
\begin{aligned}
& \ln \widetilde{\mathrm{a}}_{\mathrm{ij}} \approx\left(\operatorname{lnl}_{\mathrm{ij}}, \operatorname{lnm}_{\mathrm{ij}}, \ln _{\mathrm{ij}}\right), \mathrm{i}, \mathrm{j}=1, \ldots, \mathrm{n} . \\
& \mu_{\mathrm{ij}}\left(\ln \left(\frac{\mathrm{w}_{\mathrm{i}}}{\mathrm{w}_{\mathrm{j}}}\right)\right) \\
& = \begin{cases}\frac{\ln \left(\mathrm{w}_{\mathrm{i}} / \mathrm{w}_{\mathrm{j}}\right)-\ln \mathrm{l}_{\mathrm{ij}}}{\ln \mathrm{m}_{\mathrm{ij}}-\ln \mathrm{l}_{\mathrm{ij}}}, & \ln \left(\frac{\mathrm{w}_{\mathrm{i}}}{\mathrm{w}_{\mathrm{j}}}\right) \leq \ln \mathrm{m}_{\mathrm{ij}}, \\
\frac{\ln \mathrm{u}_{\mathrm{ij}}-\ln \left(\mathrm{w}_{\mathrm{i}} / \mathrm{w}_{\mathrm{j}}\right)}{\ln \mathrm{u}_{\mathrm{ij}}-\ln \mathrm{m}_{\mathrm{ij}}}, & \ln \left(\frac{\mathrm{w}_{\mathrm{i}}}{\mathrm{w}_{\mathrm{j}}}\right) \geq \ln \mathrm{m}_{\mathrm{ij},},\end{cases}
\end{aligned}
$$

In fact, nonlinear equations are converted to logarithmic nonlinear equations, and finally, a new objective function and related constraints are attained as follows:

$$
\begin{array}{cl}
\text { Maximize } & 1-\lambda \\
\text { Subject to } & \left\{\begin{array}{c}
\ln w_{i}-\ln w_{j}-\lambda \ln \left(\frac{m_{i j}}{l_{i j}}\right) \geq \ln l_{i j}, \\
i=1, \ldots, n-1 ; j=i+1, \ldots, n, \\
-\ln w_{i}+\ln w_{j}-\lambda \ln \left(\frac{u_{i j}}{m_{i j}}\right) \geq-\ln u_{i j}, \\
i=1, \ldots, n-1 ; j=i+1, \ldots, n, \\
w_{i} \geq 0, i=1, \ldots, n .
\end{array}\right.
\end{array}
$$

However, there is still the possibility that $\lambda$ can be negative. In order to avoid this, two non-negative deviation variables $\delta_{i j}$ and $\eta_{i j}$ for $i=1, \ldots, n-1$ and $j=i+1, \ldots, n$ are used and the following objective function and constraints LFPP are achieved: 


$$
\begin{gathered}
\text { Minimize } J=(1-\lambda)^{2}+M . \sum_{i=1}^{n-1} \sum_{j=i+1}^{n}\left(\delta_{i j}^{2}+\eta_{i j}^{2}\right) \\
\text { Subject to }\left\{\begin{array}{c}
x_{i}-x_{j}-\lambda \ln \left(m_{i j} / l_{i j}\right)+\delta_{i j} \geq \operatorname{lnl} i j \\
i=1, \ldots, n-1 ; j=i+1, \ldots, n, \\
-x_{i}+x_{j}-\lambda \ln \left(u_{i j} / m_{i j}\right)+\eta_{i j} \geq-\ln u_{i j}, \\
i=1, \ldots, n-1 ; j=i+1, \ldots, n, \\
\lambda, x_{i} \geq 0, i=1, \ldots, n, \\
\delta_{i j}, \eta_{i j} \geq 0, i=1, \ldots, n-1 ; j=i+1, \ldots, n,
\end{array}\right.
\end{gathered}
$$

By solving this problem, crisp weights are driven from a fuzzy pairwise comparison matrix.

\section{$4 \quad$ Results and findings}

This study measured the importance of social media on travel process in three different phases (pre-visit, on site, post-visit) from the perspective of Iranian travelers. It is worthwhile to know the level of social media influence on respondents' travel process in each phase and its sub categories. As mentioned earlier, in the first step of this research the hierarchy of the problem was prepared. In order to evaluate and prioritize the weights of social media utilization, three criteria in the first stage and 16 alternatives in second stage are composed. Fig. 5 demonstrates the hierarchy of criteria studied in this paper.

For the purpose of this study respondents were asked to indicate their preference with five phrases in the form of "Equally important"," Weakly more important"," Strongly more important", "Very strongly more important" and "Absolutely more important".

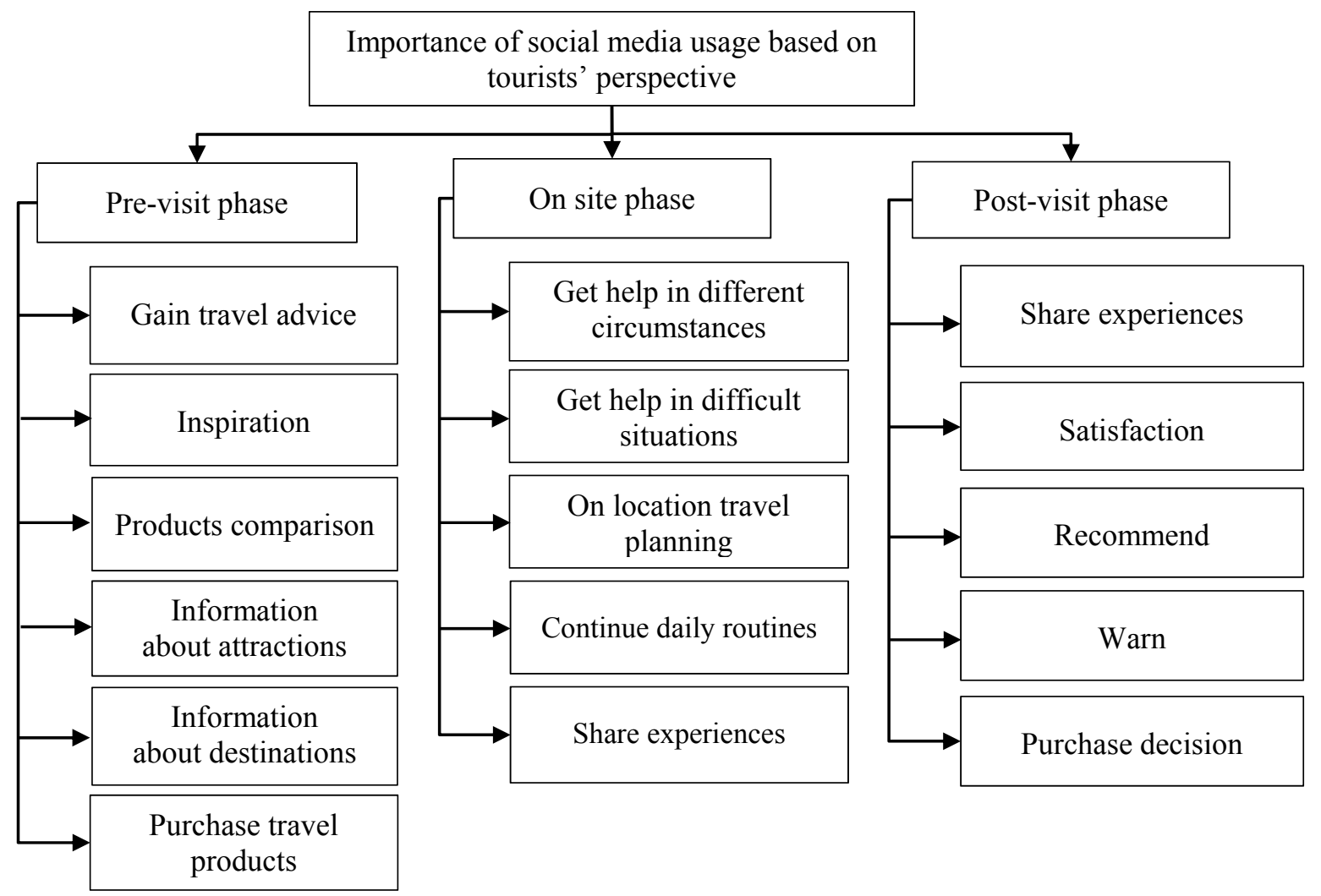

Figure 5. Hierarchy of the problem

In the second step, 36 pairwise comparison matrix were made. In the Fig. 6, a sample of such comparison is illustrated.

\begin{tabular}{|c|c|c|}
\hline$(1,1,1)$ & $(1,3,5)$ & $(1,3,5)$ \\
\hline$(0 / 2,0 / 33,1)$ & $(1,1,1)$ & $(3,5,7)$ \\
\hline$(0 / 2,0 / 33,1)$ & $(0 / 14,0 / 2,0 / 33)$ & $(1,1,1)$ \\
\hline
\end{tabular}

Figure 6. Fuzzy comparison matrix 
The weight of all criteria and alternatives were computed in the third and fourth step of this paper. The results obtained from solving the problem with LFPP and fuzzy AHP methods are presented here. Weight of each criteria gained by each method is shown in Table 3.

Table 3. The weight of criteria

\begin{tabular}{|c|c|c|c|}
\hline Method & $\begin{array}{c}\text { Pre-visit } \\
\text { phase }\end{array}$ & $\begin{array}{c}\text { On site } \\
\text { phase }\end{array}$ & $\begin{array}{c}\text { Post-visit } \\
\text { phase }\end{array}$ \\
\hline LFPP & 0.63 & 0.24 & 0.13 \\
\hline FAHP & 0.51 & 0.46 & 0.03 \\
\hline
\end{tabular}

Table 4 also shows the differences between obtained weights of each alternative using different methods.

In the last step and based on the computed weight by LFPP method, the final results are presented. As LFPP method is more accurate and as it is obvious from Table 4, fuzzy AHP method has its own limitations and errors; LFPP method results have been used for data analysis. This study results show that the pre-visit phase is very much in favor with travelers among the three phases of the travel process as shown in Fig. 7.

Table 4. The weight of alternatives

\begin{tabular}{|l|c|c|}
\hline \multicolumn{1}{|c|}{ Method } & LFPP & FAHP \\
\hline Gain travel advice & 0.36 & 0.21 \\
\hline Inspiration & 0.23 & 0.21 \\
\hline Products comparison & 0.15 & 0.21 \\
\hline Information about attractions & 0.12 & 0.20 \\
\hline Information about destinations & 0.07 & 0.17 \\
\hline Purchase travel products & 0.07 & 0.00 \\
\hline $\begin{array}{l}\text { Get help in different } \\
\text { circumstances }\end{array}$ & 0.39 & 0.28 \\
\hline Get help in difficult situations & 0.31 & 0.30 \\
\hline On location travel planning & 0.15 & 0.25 \\
\hline Continue daily routines & 0.09 & 0.17 \\
\hline Share experiences (on site) & 0.06 & 0.00 \\
\hline Share experiences (post-visit) & 0.45 & 0.30 \\
\hline Satisfaction & 0.23 & 0.27 \\
\hline Recommend & 0.16 & 0.26 \\
\hline Warn & 0.09 & 0.18 \\
\hline Purchase decision & 0.07 & 0.00 \\
\hline
\end{tabular}

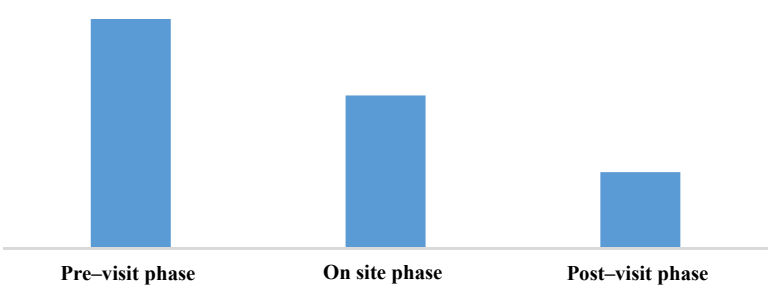

Figure 7. Rank of the three phases of travel process

- Pre-visit phase

In this study, on the pre-visit phase, the level of influence was evaluated in terms of (a) gain travel advice, (b) inspiration, (c) products comparison, (d) information about attractions, (e) information about destinations, and (f) purchase travel products. As a result, among alternatives used in pre-visit phase, gain travel advice has the most importance for travelers while using social media. In the contrary, information about both destination and purchase travel products have the least usage among travelers in pre-visit phase as shown in Fig. 8.

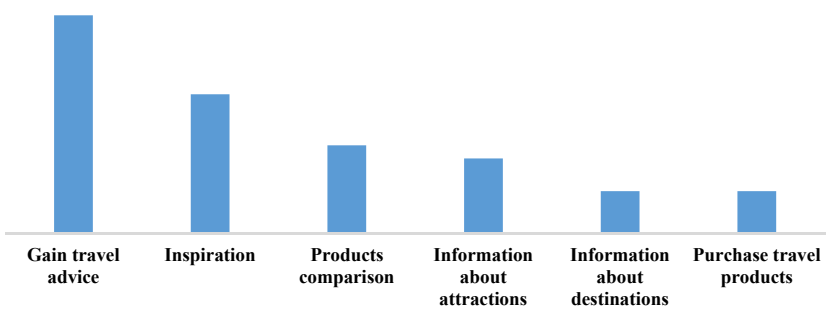

Figure 8. Rank of the pre-visit phase alternatives

- On site phase

As mentioned, the study measured the importance of social media in the on-site phase as well. For this phase, level of influence was evaluated in terms of (a) get help in different circumstances, (b) get help in difficult situations, (c) on location travel planning, (d) continue daily routines, and, (e) share experiences.

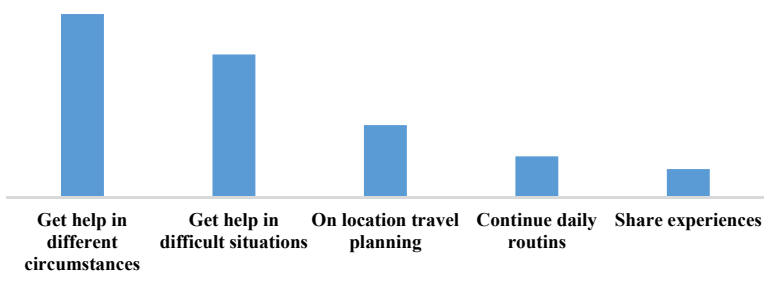

Figure 9. Rank of the on-site phase alternatives 
The results in Fig. 9 shows that, in on-site phase, the travelers largely use social media for getting help in different circumstances which respondents use it in order to make their trip as pleasant as possible, second comes getting help in difficult situations in order to cope with unexpected circumstances. At the other end of the ranking sharing experiences while traveling fell into the lowest level in the onsite visit phase.

- Post-visit phase

Impact of social media on post-visit phase was similarly measured. For post-visit phase, level of influence was evaluated in terms of (a) share experiences, (b) satisfaction, (c) recommend, (d) warn, and (e) purchase decision. The results show that social media in post-visit phase has the least usage among travelers. As shown in Fig. 10, respondents stated that they use social media predominantly for sharing experiences with friends and other travelers. Satisfying inner desire by reading and writing about travelrelated experiences took the second place. Providing needed information for potential travelers (purchase decision) placed at the bottom of the ranking.

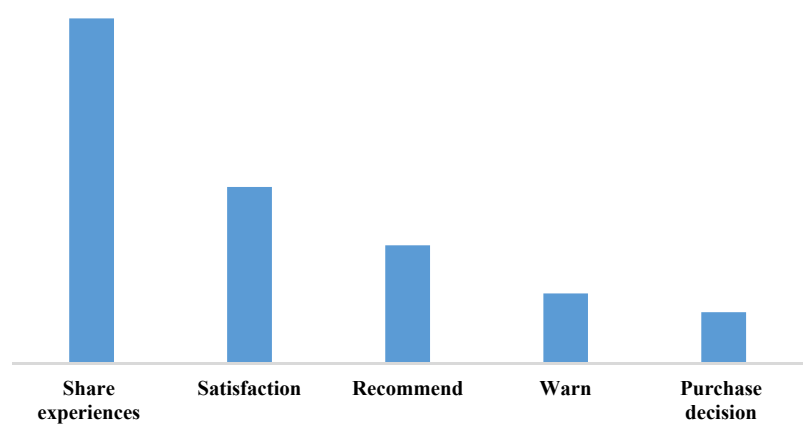

Figure 10. Rank of the post-visit phase alternatives

As the result discussed above shows that social media in pre-visit phase has the most usage among travelers, therefore, comparing to other studies, this finding is similar to that of Cox et al. [63] who found that social media is mostly used for pre-visit phase and it is in contrast with Fotis et al. [38] who found that social media is mainly used in the post-visit phase.

\section{$5 \quad$ Discussion and conclusion}

According to the literature review social media is broadly used for information search during travel process. Jepsen [64] argued that traditional information source is replacing by social media, and since then many research have been done and all the results were in the favor of this argument. Web 2.0 or social media has shown a tremendous impact on the travel and tourism industry, and its growth and popularity continues among consumers. The high importance of social media usage in travel make it an indispensable part of tourism market. Because of this, tourism industry seems to be heading toward revolution.

Till now, many studies have tried to investigate the role of social media in travel and tourism industry, however this study tried to identify the degree to which social media is important in each phase of travel from tourist perspective. This study findings show that Iranian travelers use social media throughout all phases of the travel: pre-visit, on site and post-visit. However, as shown in [38], travelers use social media for different purposes and in different extent. The results of this study suggest that the most usage of social media is on pre-visit phase while post-visit has the least usage. This study shows that Iranian travelers use social media mainly to share experiences (post-visit phase), get help in different circumstances, and gain travel advice.

The main limitation of this study is related to the number of respondents. This article only asked for Iranian experts' opinion, although it was sufficient for the purpose of the present study, but for generalization of the findings to a larger population more studies need to be conducted. Another limitation is related to the type of respondents. As travelers are the one who actually use social media in their trips, their opinions are important and should be considered as well.

Based on the findings of this study, using social media in three different phases of travel, pre-visit in specific, has a significant effect on consumers' behavior and therefore the tourism industry should place more emphasis in this phase of the travel process.

This study is an evidence to corroborate the importance of social media from consumer perspective and suggests that in order to improve their position in tourism market, tourism industry should acknowledge the user's opinion. It should also be 
noted that to validate the findings of this study more similar research are needed to be carried out.

\section{$6 \quad$ References}

[1] Munar A.M. (2012) - Social media strategies and destination management. Scandinavian Journal of Hospitality and Tourism, 12(2), 101120.

[2] Law R., Xiang Z. (2013) - Journal of Travel \& Tourism Marketing Special Issue on Social Media - Preface. Journal of Travel \& Tourism Marketing, 30(1-2), 1-2.

[3] Hays S., Page S.J., Buhalis D. (2013) - Social media as a destination marketing tool: its use by national tourism organisations. Current Issues in Tourism, 16(3), 211-239.

[4] Instagram (2015) - About us. Retrieved 30 July, 2015, from https://instagram.com/about/us/

[5] TripAdvisor. (2015) - Fact Sheet. Retrieved 8 August, 2015, from

http://www.TripAdvisor.com/PressCenter-c4-

Fact Sheet.html

[6] Litvin S.W. Goldsmith R.E., Pan B. (2008) Electronic word-of-mouth in hospitality and tourism management. Tourism management, 29(3), 458-468.

[7] Buhalis D. (1998) - Strategic use of information technologies in the tourism industry. Tourism management, 19(5), 409-421.

[8] Kaplan A.M., Haenlein M. (2010) - Users of the world, unite! The challenges and opportunities of Social Media. Business horizons, 53, 59-68.

[9] Nielsen (2009) - Global Advertising Consumers Trust Real Friends and Virtual Strangers the Most. Retrieved 27 July, 2015, from http://www.nielsen.com/us/en/insights/news/200 9/global-advertising-consumers-trust-realfriends-and-virtual-strangers-the-most.html

[10] eBizMBA (2015) - Top 15 Most Popular Social Networking Sites. Retrieved 10 August, 2015, from http://www.ebizmba.com/articles/socialnetworking-websites

[11] eBizMBA (2015) - Top 15 Most Popular Travel Websites. Retrieved 10 August, 2015, from http://www.ebizmba.com/articles/travel-websites
[12] Google/OTX. (2011) - Traveler's Road to Decision. Retrieved 27 July, 2015, from http://www.gstatic.com/ads/research/en/2011_Tr avelersRoadtoDecision2011.pdf

[13] Yoo K.H., Gretzel U., Zach F. (2011) - Travel opinion leaders and seekers: Springer.

[14] Werthner H., Klein S. (1999). Information technology and tourism: a challenging ralationship: Springer-Verlag Wien.

[15] Aldebert B., Dang R.J., Longhi C. (2011). Innovation in the tourism industry: The case ofTourism@. Tourism management, 32(5), 1204-1213.

[16] Fuchs M., Höpken W., Föger A., Kunz M. (2010) - E-business readiness, intensity, and impact: an Austrian destination management organization study. Journal of Travel Research, 49(2), 165-178.

[17] Doolin B., Burgess L., Cooper J. (2002) - Evaluating the use of the Web for tourism marketing: a case study from New Zealand. Tourism management, 23(5), 557-561.

[18] Gretzel U., Kang M., Lee W. (2008) - Differences in consumer-generated media adoption and use: A cross-national perspective. Journal of Hospitality \& Leisure Marketing, 17(1-2), 99120.

[19] World Tourism Organization (2008) - Handbook on E-marketing for Tourism Destinations. Madrid: World Tourism Organization.

[20] Tussyadiah I.P., Fesenmaier D.R. (2009) - Mediating tourist experiences: Access to places via shared videos. Annals of Tourism Research, 36(1), 24-40.

[21] Wenger A. (2008) - Analysis of travel bloggers' characteristics and their communication about Austria as a tourism destination. Journal of Vacation Marketing, 14(2), 169-176.

[22] Xiang Z., Gretzel U. (2010) - Role of social media in online travel information search. Tourism management, 31(2), 179-188.

[23] eMarketer (2008). Online Reviews Sway Shoppers. Retrieved 29 July, 2015, from http://www.emarketer.com/Article/OnlineReviews-Sway-Shoppers/1006404 
[24] Chung J.Y., Buhalis D. (2008) - Information needs in online social networks. Information Technology \& Tourism, 10(4), 267-281.

[25] Casaló L.V., Flavián C., Guinalíu M. (2011) Understanding the intention to follow the advice obtained in an online travel community. Computers in Human Behavior, 27(2), 622-633.

[26] Munar A.M., Jacobsen J.K.S. (2014) - Motivations for sharing tourism experiences through social media. Tourism management, 43, 46-54.

[27] Bosun P., Tenescu A., Dima I.C. (2014) - Informational stocks and e-logistics management of a tourism company. International Letters of Social and Humanistic Sciences(16), 75-85.

[28] Buhalis D., Wagner R. (2013) - E-destinations: Global best practice in tourism technologies and applications: Springer.

[29] Strachan I.G. (2013) - Take Me to My Paradise: Tourism and Nationalism in the British Virgin Islands. Colleen Ballerino Cohen. New Brunswick NJ: Rutgers University Press, 2010. xiv+ 270 pp.(Paper US \$25.95). New West Indian Guide/Nieuwe West-Indische Gids, 87(3-4), 450-451.

[30] Teng C.C., Horng J.S., Hu I. C. (2014) - Taiwanese Students' Knowledge of Energy Conservation and Carbon Reduction in Hospitality and Tourism: Developing and Testing an Assessment Instrument. Journal of Hospitality \& Tourism Education, 26(3), 99-112.

[31] Xiang Z., Pan B., Fesenmaier D.R. (2013) Search Engine Marketing for Tourist Destinations.

[32] Fesenmaier D.R., Xiang Z., Pan B., Law R. (2010) - A framework of search engine use for travel planning. Journal of Travel Research, 0047287510385466.

[33] Hay B. (2010) - Twitter Twitter-But who is listening? a review of the current and potential use of Twittering as a tourism marketing tool.

[34] Amaro S., Duarte P. (2015) - An integrative model of consumers' intentions to purchase travel online. Tourism management, 46, 64-79.

[35] Jensen J.M. (2012) - Shopping orientation and online travel shopping: the role of travel experience. International Journal of Tourism Research, 14(1), 56-70.
[36] Wang D., Fesenmaier D.R. (2013) - Transforming the travel experience: The use of smartphones for travel: Springer.

[37] Kurup S. (2014) - Study on Consumer Attitude Towards Social Media Usage in Tourism. International Journal of Logistics \& Supply Chain Management Perspectives, 2(4), 431-436.

[38] Fotis J., Buhalis D., Rossides N. (2012) - Social media use and impact during the holiday travel planning process: Springer-Verlag.

[39] Li H., Hua X.-S. (2010) - Melog: mobile experience sharing through automatic multimedia blogging. Paper presented at the Proceedings of the 2010 ACM multimedia workshop on Mobile cloud media computing.

[40] Fotis J., Buhalis D., Rossides N. (2011) - Social media impact on holiday travel planning: The case of the Russian and the FSU markets. International Journal of Online Marketing (IJOM), 1(4), 1-19.

[41] Lenhart A., Fox S. (2010) - Bloggers-a portrait of the internet's new storytellers (2006).

URL http://www. pewinternet.org/Reports/2006/Bloggers.aspx.

[42] Yoo K.H., Gretzel U. (2008) - What motivates consumers to write online travel reviews? Information Technology \& Tourism, 10(4), 283295.

[43] Wilson E., Small J., Harris C. (2012) - Editorial introduction: Beyond the margins? The relevance of critical tourism and hospitality studies. Journal of Hospitality and Tourism Management, 19, e1.

[44] Sparks B.A., Browning V. (2010) - Complaining in cyberspace: The motives and forms of hotel guests' complaints online. Journal of Hospi-tality Marketing \& Management, 19(7), 797-818.

[45] Huang Y., Basu C., Hsu M. K. (2010). Exploring motivations of travel knowledge sharing on social network sites: an empirical investigation of US college students. Journal of Hospitality Marketing \& Management, 19(7), 717-734.

[46] Satty T. L. (1980) - The analytic hierarchy process: New York: McGraw-Hill New York.

[47] Safari H., Aghighi M., Rabor F.M., CruzMachado, V. A. (2014) - A New Approach to Job Evaluation Through Fuzzy SIR. Paper presented at the Proceedings of the Eighth Interna- 
tional Conference on Management Science and Engineering Management.

[48] Safari H., Khanmohammadi E., Hafezamini A., Ahangari S.S. (2013) - A New Technique for Multi Criteria Decision Making Based on Modified Similarity Method. Middle-East Journal of Scientific Research, 14(5), 712-719.

[49] Wu H.H., Tsai Y.N. (2012) - An integrated approach of AHP and DEMATEL methods in evaluating the criteria of auto spare parts industry. International Journal of Systems Science, 43(11), 2114-2124.

[50] Lin C.Y. Chung E.Y. (2014) - Evaluating the criteria of social media network users. Quality \& Quantity, 1-12.

[51] Zahedi F. (1986) - The analytic hierarchy process-a survey of the method and its applications. interfaces, 16(4), 96-108.

[52] Sarkis J., Sundarraj R. (2001) - Strategic Evaluation.

[53] Jiang X., Zheng B., Wang L. (2009) - The coupled method fuzzy-AHP applys to solve multicriteria decision making problems. WSEAS Transactions on Mathematics, 8(11), 657-666.

[54] Lam K.C., Lam M.C.K., Wang D. (2008) $M B N Q A$-oriented self-assessment quality management system for contractors: fuzzy AHP approach. Construction Management and Economics, 26(5), 447-461.

[55] Chang D.Y. (1996) - Applications of the extent analysis method on fuzzy AHP. European journal of operational research, 95(3), 649-655.

[56] Wang Y.M., Luo Y., Hua Z. (2008) - On the extent analysis method for fuzzy AHP and its applications. European journal of operational research, 186(2), 735-747.
[57] Wang Y.M., Chin K.S. (2011) - Fuzzy analytic hierarchy process: A logarithmic fuzzy preference programming methodology. International Journal of Approximate Reasoning, 52(4), 541553.

[58] Massanet S., Riera J.V., Torrens J., HerreraViedma, E. (2014) - A new linguistic computational model based on discrete fuzzy numbers for computing with words. Information Sciences, 258, 277-290.

[59] Rodríguez R.M., Martínez L., Herrera F. (2013) - A group decision making model dealing with comparative linguistic expressions based on hesitant fuzzy linguistic term sets. Information Sciences, 241, 28-42.

[60] Bozbura F.T., Beskese A. (2007) - Prioritization of organizational capital measurement indicators using fuzzy AHP. International Journal of Approximate Reasoning, 44(2), 124-147.

[61] Van Laarhoven P., Pedrycz W. (1983) - A fuzzy extension of Saaty's priority theory. Fuzzy sets and Systems, 11(1), 199-227.

[62] Mikhailov L. (2003) - Deriving priorities from fuzzy pairwise comparison judgements. Fuzzy sets and systems, 134(3), 365-385.

[63] Cox C., Burgess S., Sellitto C., Buultjens J. (2009) - The role of user-generated content in tourists' travel planning behavior. Journal of Hospitality Marketing \& Management, 18(8), 743-764.

[64] Jepsen A.L. (2006) - Information Search in Virtual Communities: Is it Replacing Use of OffLine Communication? Journal of Marketing Communications, 12(4), 247-261. 